$1447(1969)$.

11. (ihadimi, H.: Hyperlysinemia. In: J. B. Stantury, J. B. Wyngatarden, and D) S. Fredrickson: The Metabolic Basis of Inherited Disease, Id. 3, p. 39.3 (McCiraw-Hill Book Co.. Inc.. New York, 1972).

12. Ghadimi. H., Binnington, V. I., and Pecora, P.: Hyperlysinemia associated with retardation. New Fngl. J. Med. 273: 723 (1965).

13. Kang, E. S.. Snodgrass. P. J., and Gerald, P. S.: Methylmalonyl coenzyme A racemase defect: Another cause of methylmalonic aciduria. Pediat. Res.. 6 $875(1472)$

14. Keating, J. P.. Feigin, R. D.. Tenenbaum, S. M.. and Hillman, R. \&.. Hyperglycinemia with ketesis due to a defect in isoleucine metabolism: A preliminary report. Pediatrics, $50.890(1972)$.

15. Landes, R. D.. Avery, (i. B., Walker, F. A., and Hsia, Y. F.. Propionyl-C oA carboxylase deficiency (propionicalcidemia): Another cause of hyperammonemiat. Pediat. Res., 6: 394 (1972).

16. Okuda, H... and Fujii. S.: A direct colorimetric defermination of hlood ammonia. Tokushima J. Exp. Med., 12: 11 (1964)

17. Oyanatgi. K., Sogawa, H., Sato. S.. Orii, T.. Nakat, T.. and Fujita. S. Clinical and biochemical studies on periodic hyperammonemia with hyperIysinemia and homocitrullinuria. Tohoki J Exp. Med.. 120:105 (1976)

18. Rochovansky, O.. and Ratner, S.: Biosynthesis of urea. Xill. Further studic on argininosuccinate synthetase: Substrate affinity and mechanism of atction
J. Biol. (hem.. 242:38.34(1967)

14. Ryan, W. I... Barak. A. J.. and Johnson, R. J. I ysine, homocitrulline and homoarginine metabolism by the isolated perfused rat liver. Arch. Biochem. Biophys.. 12.3: 294 (1968)

20. Ryan, W. 1.. Johnoon, R. J., and Dimari, S.: Homoarginine synthesis by rat kidney. Arch. Biochem. Biophys, /3/: 521 (1969).

21. Scott-Fmuakpor, A.. Higgins, J. V.. and Kohrman, A. F.: Citrullinemia: A new case with implications concerning adaptation we dective urea synthesis. Pediat. Res.. 6: 626 (1972).

22. Strandholm. J. J., Buist, N. R. M.. and Kennawaty, N. (;.: Homoargininosuccinic acid synthesis hy an enzyme from pig kidney. Biochim. Biophws. Actat 2.37: $293(1971)$

23. Tomlinson. S., and Westall. R. (i.: Argininosuccinic aciduria, argininosuctinase and arginase in human blood cells. (lin. Sci.. 26: $261(1964)$

24. Woody, N. ( . I Iyperlysinemia. Amer. J. Dis. (hild.. 108: $543(1964)$

25. Woody, N. ( . . Hutzler, J., and Dancis, J.: Further studies of hyperlysinemia. Amer. J. Dis. (hild.. 112:577(1960).

26. Informed consent was obtained for all subjects in this study.

27. Requests for reprints should he addressed to: H. Sogawa, M.D.. Department of Pediatrics. Sapporo Medical College. S.1 W.17 Sapporo (Japan).

28. Received for publication November 19.1976.

29. Accepted for publication February 15,1977
Cholesterol familial hypertriglyceridemia triglyceride type IV diet

type IV hyperlipoproteinemia

\title{
Familial Hypertriglyceridemia in Children: Dietary Management
}

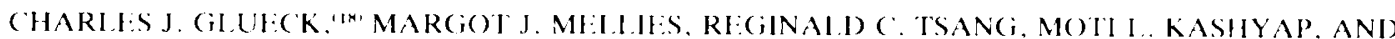 \\ PAUIA M. STIINIR

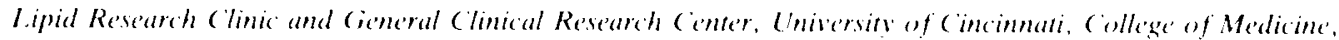 \\ (incinnati, Ohio, USA
}

\section{Summary}

This study was designed to evaluate prospectively the continuing effects of dietary management in 44 children with familial hypertriglyceridemia. For obese children, weight reduction programs were instituted by metabolic dietitians. For nonobese children, for obese children with successful weight reduction (or for those who could not lose weight but would follow an altered diet), a modification of the National Institutes of Health (NIH) type IV diet was provided. Adherence to the diet program was monitored by monthly reassessment for 6 months in the outpatient clinic. In 4.3 children whose average age was 1.3 years at the time of diagnosis, mean \pm SE plasma triglycerides were reduced after 6 months of weight reduction-NIH type IV diet from $253 \pm 33$ to $116 \pm 8 \mathrm{mg} / \mathrm{dl}, P<0.01$. After 6 months on diet, the group mean decrement in weight $(1 \pm 1 \mathrm{~kg})$ was not significant, and decrements in weight failed to correlate with decrements in plasma triglycerides, $r=0.131$. Despite this failure to reduce weight appreciably, after 6 months on diet plasma triglyceride levels were reduced to normal $(<140 \mathrm{mg} / \mathrm{dl}$ ) in 32 of the 43 children. At 8 months' follow-up in 13 children, mean plasma triglyceride was $170 \pm 31 \mathrm{mg} / \mathrm{dl}$, having been 290 \pm 86 at time of diagnosis, $P<0.01$. Plasma triglyceride levels at 8 months were normal in 5 of the 13 children. Plasma triglycerides were normal in 4 of 5 children with evaluation at 1 year, in 3 of 7 at 18 months, and in 4 of 14 at 22-26 months. When weight gain was proportionately greater than accretion of height, and where no attention to either caloric intake or composition was given, triglycerides remained elevated, whereas dietary adherence was generally accompanied by reduced or normal triglycerides. Amelioration of familial hypertriglyceridemia on the NIH type IV diet is a realizable goal in children, but requires persistent, repetitive reexamination and reinstruction.

\section{Speculation}

Dietary management of pediatric familial hypertriglyceridemia may be important as a primary. longitudinal approach to reduction of the increased atherosclerotic risk attendant to familial hypertriglyceridemia.

Primary hypertriglyceridemia occurs in $20 \%$ of children (under age 21) born to parents with familial hypertriglyceridemia (10). Substantial obesity is associated with the pediatrie expression of familial hypertriglyceridemia in $30-60 \%$ of affected children (9, 10). Unlike pediatric familial hypercholesterolemia (7. 11). where dietary intervention provides only limited lipid lowering. most children with familial hypertriglyceridemia will normalize their triglycerides on a weight reducing/type IV (5) diet $(9,10)$. Amclioration of pediatric hypertriglyceridemia on diet may be important as a primary. Iongitudinal approach to reduction of increased atherosclerotic risk reported in some (2, 3). but not all adults (1) with famial hypertriglyceridemia. 
In children with familial hypercholesterolemia the initial moderate reductions in plasma cholesterol on diet are less matred with passage of time $(7,8,11)$. This study was designed to evaluate prospectively the continuing effects of dietary management in 44 children with familial hypertriglyceridemia.

\section{MATERIALS AND METHODS}

\section{PATIENTS: HYPERTRIGLYCFRIDEMIC CHILDREN AND YOUNC ADUI.TS}

Diagnoses of pediatric familial hypertriglyceridemia were made using previously described criteria $(9,10)$. Of the 44 hypertriglyceridemic children in the current report, basal kindred information has previously been published in one study for $23(10)$ and in another study for 16 patients (9). All of the 44 hypertriglyceridemic children came from kindreds where one propositus parent and at least one additional first or second degree relative had primary endogenous hypertriglyceridemia (9, 10). Three children (two with type III hyperlipoproteinemia, patients $/ 4$ and 15 ) and one with type IV (patient 16 ) came from kindreds with familial type IlI (6). All children thus came from kindreds with documented familial hypertriglyeeridemia, predominantly type IV hyperlipoproteinemia (4, 8-10). These kindreds were probably biased toward those with the more severe forms of familial hypertriglyeeridemia $(4,8-10)$. The primary nature of the hypertriglyceridemia was defined by the exclusion of other disorders known to produce secondary hypertriglyceridemia $(4,8-10)$.

\section{ANALYTIC METHODS}

Blood samples were obtained after a 12-hr overnight fast. All plasmas were visually inspected (after sitting overnight at $4^{\circ}$ ) to evaluate for the presence of chylomicrons floating as a "cream layer" at the plasma surface. In subjects 37 and $4 /$ (Table 1 ) with initial plasma triglycerides 1.320 and $968 \mathrm{mg} / \mathrm{dl}$, heavy tailing of chylomicron-triglyceride into the electrophoretic origin made it difficult to distinguish between type IV and type $V$ lipoprotein patterns (4, 8-10). Plasmal cholesterol and triglyceride were quantitated following the lipid Rescarch (Clinicis methodology (12).

\section{STUDY PROTOCOL}

After identification of primary hypertriglyceridemia by two separate measurements while on ad libitum diet. individualized dietary programs were devised for each child. For obese children (9.10). weight reduction programs were instituted by metabolic dietitians. For nonobese children, obese children with successful weight reduction (or for those who could not lose weight but would follow an altered diet), a modification of the NIH type IV diet was provided $(5,9)$. This diet included $20 \%$ of the calories as protein, $40 \%$ as fat. $40 \%$ as carbohydrate, with a polyunsaturate/saturate ratio of $1.5 / 1$. Adherence to the diet program was monitored by monthly reassessment for 6 months in the outpatient clinic.

For continued evaluation past 6 months, each subject was urged to return every $2-4$ months. Follow-up studies past 6 months were carried out in 19 of the 44 children (Table 2). In the 2.5 children with no studies reported beyond month 6.8 are scheduled for future resampling. 9 are being cared for by private pediatricians, 6 have moved out of town, and 2 are at out of town colleges. At each follow-up visit, adherence to the suggested dietary regimen was assessed after obtaining at 24-hr diet recall. Because of the highly limited, semiquantitative to qualitative nature of the assessment of dietary adherence, children in the continuing evaluation program could only be identified as: (1) following none of the suggested dietary recommendations, (2) having satisfactory dietary adherence, (3) unable to provide sufficient information to allow any judgement in regard to adherence (Table 2).

\section{STATISTICAI. ANAI.YSES}

Relationships between the prediet baseline triglyceride levels and those during follow-up were studied using the paired Wilcoxon nonparametric test for differences (1.3). Relationships between changes in weight and changes in triglyceride levels were evaluated using regression analysis $(14)$ or nonparametric regression analyses (15).

\section{RESUITS}

\section{EFFECTS OF DIET ON PLASMA TRIGIYCERIDES AT 6 AND 8} MONTHS' FOLLOW-UP

Mean $( \pm \mathrm{SE})$ age at the time of diagnosis was $1.3 .3 \pm 0.6$ years (Table 1). Forty-three children were available for follow-up 6 months after initial diagnosis, having followed the weight reduction/type IV diet program. Mean ( \pm SF) fasting plasma triglycerides for the group fell from $25.3 \pm 33 \mathrm{mg} / \mathrm{dl}$ to $116 \pm 8, P<0.01$ (Table 1). Mean plasma cholesterol was moderately reduced from $194 \pm 6 \mathrm{mg} / \mathrm{dl}$ to $181 \pm 5$ at 6 months, $P<0.05$. Plasma triglyceride levels were reduced to normal $(<140 \mathrm{mg} / \mathrm{dl})(4)$ at 6 months in 32 of the 4.3 children (Table 1 ).

At 6 months' follow-up for the 4.3 children. mean \pm SE weight loss was $1 \pm 1.09 \mathrm{~kg}, P>0.1$ (Table 1 ). The decrements in weight failed to correlate significantly with decrements in triglyeeride, $r=0.131$.

At 8 months follow-up (Table 2), 13 children were available for study. Mean \pm SE plasma triglyceride in this group. $290 \pm$ $86 \mathrm{mg} / \mathrm{dl}$ prior to diet, was $170 \pm .31 \mathrm{mg} / \mathrm{dl}$ at 8 months. $P<$ 0.01 . At 8 months, plasma triglyceride levels were normal in 5 of 13 children. At 8 months, mean weight in the 1.3 children had increased $2.7 \pm 1 \mathrm{~kg}$ from baseline levels. $P=0.1$

\section{FFFECTS OF DIFT ON PI.ASMA TRICIIYCERIDE, 1-2-YEAR FOIIOW-} UP

Follow-up data on plasma triglyceride levels for 1-2-year periods following diagnosis are summarized in Table 2. Of the five children seen at 1 year, plasma triglyeerides were normal in the four who adhered to the diet. In subject 15, weight increased $3 \mathrm{~kg}$ over baseline, height was unchanged, and triglycerides increased. Of the seven children seen at 18 months. plasma triglycerides were normal in three, had risen above baselineprediet levels in two. and were slightly below baseline levels in two. In the two children with recrudescent hypertriglyceridemia, 24-hr dietary recall revealed no efforts to follow the suggested diet in one (subject 7), whereas in the other (subject 44$)$, the re was a $12-\mathrm{kg}$ increase in weight over baseline.

Fourteen children were studied for 22-26 months following initial diagnosis (Table 2). Four (subjects 6, 8, 28, 44) retained normal triglyceride levels. Although not reduced to normal levels, triglycerides fell $15 \% .24 \% .+5 \%$. and $88 \%$ in four additional children, respectively, and rose $10 \%, 16 \%, 19 \%, 21 \%$, and $46^{\circ} ;$ above baseline in five children. In the six children whose triglyeerides rose or remained at baseline (subjects 9, 11 , $31,34,38,55 \%$, five followed no suggested diet.

For those children studied at 12,18, and 22-26 months, the ratio of the change $(د)$ in weight to the change in height $(\Delta \mathrm{Wt} /$ $\Delta \mathrm{Ht}$ ) failed to correlate with the change in triglyceride ( $\triangle \mathrm{TC}(\mathrm{i}), r$ $=0.20$. For those children during these periods whose triglyceride increased above baseline, $J W t / \Delta H t$ and $J T C$ correlated significantly $(15), r=0.68 . P<0.05$, indicating the influence of disproportionate weight gain on plasma triglycerides.

\section{DISCUSSION}

Approximately $20 \%$ of children (under age 21 ) at genetic risk for familial hypertriglyceridemia have primary elevations of fasting plasma triglycerides (10), and many are considerably overweight at the time of initial diagnosis (9,10). Their obesity and their excessive intake of calories, saturated fatty acids, and 
Table 1. Baseline cholesterol and triglyceride, and levels after 6 months of diet (milligrams per ml)

\begin{tabular}{|c|c|c|c|c|c|c|c|c|}
\hline \multirow{2}{*}{$\begin{array}{c}\text { Subject } \\
\text { no. }\end{array}$} & \multirow[b]{2}{*}{ Age } & \multirow[b]{2}{*}{ Sex } & \multicolumn{2}{|c|}{ Baseline } & \multicolumn{2}{|c|}{ At 6 months } & \multicolumn{2}{|c|}{ Weight } \\
\hline & & & Cholesterol & Triglyceride & Cholesterol & Triglyceride & Baseline & At 6 months \\
\hline$I(R H)$ & 9 & $\mathrm{~F}$ & 244 & 146 & 225 & 114 & 47 & 43 \\
\hline $2(M B)$ & 17 & $\mathbf{M}$ & 198 & 300 & 147 & 180 & 99 & 9.3 .7 \\
\hline $3(M J)$ & 15 & $\mathbf{F}$ & 199 & 197 & 158 & 98 & 61 & 6.3 \\
\hline $4(A E)$ & 14 & $\mathrm{~F}$ & 206 & 222 & 20.3 & 140 & 100 & 99.5 \\
\hline $5(G H)$ & 12 & $\mathbf{M}$ & 1.34 & 188 & 187 & 120 & 66.8 & 64.6 \\
\hline $6(J C)$ & 13 & $\mathrm{~F}$ & 2.31 & 34 & 220 & 128 & 47 & 49 \\
\hline $7(P S)$ & 11 & $\mathrm{~F}$ & 21.3 & 3.32 & 205 & 107 & 58.6 & 56.6 \\
\hline $8(J R)$ & 1.3 & $\mathbf{M}$ & 218 & 400 & 182 & 172 & 79.2 & 79.8 \\
\hline $\left.9(R)^{\circ}\right)$ & 11 & $\mathbf{M}$ & 190 & 202 & 193 & 60 & 61.8 & 60 \\
\hline 1010() & 8 & $\mathrm{~F}$ & 144 & 154 & 112 & 2.3 & 25.4 & 26.8 \\
\hline $11(\mathrm{LH})$ & 11 & $\mathrm{~F}$ & 199 & 148 & 185 & $1+9$ & 61 & 6.3 .7 \\
\hline $12(F B)$ & 15 & $M$ & 1.56 & 253 & 253 & 106 & 103.5 & 89.5 \\
\hline $1.3(T R)$ & 7 & $F$ & 178 & 21.3 & 195 & 170 & 54 & 55 \\
\hline $14(S E)$ & 17 & $\mathrm{~F}$ & 139 & 221 & 176 & 2.32 & 104 & 105 \\
\hline $15(\mathrm{CH})$ & 21 & $M$ & 34.3 & 217 & 208 & 102 & 66 & 64 \\
\hline $16(\mathrm{CH})$ & 17 & $\mathrm{~F}$ & 188 & $160)$ & 178 & 74 & 56 & 55.1 \\
\hline $17(J J)$ & 17 & $\mathbf{M}$ & 202 & 272 & 129 & 102 & 113 & 7.3 \\
\hline $2 I(L A)$ & 12 & $\mathrm{~F}$ & 156 & 181 & 171 & 125 & 68 & 66 \\
\hline $22(R A)$ & 1.3 & $\mathrm{~F}$ & 248 & 308 & 226 & 1.34 & 8.5 & 84 \\
\hline $23(B A)$ & 19 & $\mathrm{~F}$ & 280 & 201 & 271 & 154 & 82 & 80 \\
\hline $24(L W)$ & 12 & $\mathrm{~F}$ & 152 & 194 & 150 & 89 & 50.2 & 53 \\
\hline 25 (CS) & 3 & $M$ & 170 & 158 & 174 & 64 & 17 & 18 \\
\hline $26(D N)$ & 14 & M & 193 & 220 & 201 & 138 & 68 & 68 \\
\hline $28(L . I)$ & 13 & $\mathrm{~F}$ & 200 & 210 & 200 & 90 & 48 & 47 \\
\hline $30(E W)$ & 16 & $\mathrm{~F}$ & 164 & 340 & 140 & 210 & 66.2 & 66 \\
\hline $31(D S)$ & 21 & $M$ & 189 & 187 & 129 & 158 & 75 & 74 \\
\hline $32(T U)$ & 14 & $\mathrm{~F}$ & 197 & 176 & 153 & 4.3 & 50 & 48 \\
\hline $3.3(\mathrm{JH})$ & 18 & $M$ & 196 & 210 & $19 x$ & 230 & 77.3 & 77.6 \\
\hline $.34(T Y)$ & 17 & $M$ & 186 & 400 & 199 & 122 & 81 & 8.5 \\
\hline $3.5(M Y)$ & 22 & $\mathrm{M}$ & 224 & 154 & 203 & 116 & $8 x$ & 91 \\
\hline $36(K W)$ & 14 & $\mathrm{~F}$ & 16.5 & 192 & 152 & 42 & 59.1 & 58.6 \\
\hline $37(E S)$ & 17 & $\mathrm{~F}$ & 246 & 1.320 & 159 & 185 & 66.4 & 6.3 \\
\hline $38(M S)$ & 13 & $\mathbf{M}$ & 186 & 196 & 188 & 81 & 55 & 5.3 \\
\hline $39(K B)$ & 1.3 & $M$ & 128 & 158 & 120 & 118 & 55 & 54.2 \\
\hline $40(B U)$ & 12 & $\mathrm{~F}$ & 164 & 1.58 & $14 x$ & 74 & 46.2 & 47 \\
\hline $4 l(T U)$ & 9 & $M$ & 255 & 968 & 172 & 141 & 26 & 24 \\
\hline $42(J N)$ & y & $\mathrm{F}$ & 189 & 147 & 174 & 69 & 24 & 36.8 \\
\hline $44(G H)$ & 11 & $M$ & 2.37 & 142 & 253 & 56 & 56 & 56.4 \\
\hline $47(\mathrm{DJ})$ & 7 & $\mathrm{~F}$ & 1.37 & 144 & 162 & 120 & 21 & 22.2 \\
\hline $50(B V)$ & 11 & $\mathbf{F}$ & 195 & 149 & 212 & 6.3 & 45 & 46 \\
\hline $51(R V)$ & 1.3 & $M$ & 179 & 140 & 164 & 60 & 47 & 47.1 \\
\hline $52(M M)$ & 6 & $\mathrm{~F}$ & 168 & 145 & 1.38 & 30 & 205 & 20.8 \\
\hline $54(R D)$ & 14 & M & 168 & 170 & 168 & 118 & 91 & 90 \\
\hline $\bar{x}$ & 13.3 & & 194.4 & 2534 & $18099^{\prime}$ & $115.5^{2}$ & 62.2 & 60.9 \\
\hline SI: & .6 & & 6.4 & 32.6 & 5.4 & 7.5 & 3.6 & 3.3 \\
\hline
\end{tabular}

carbohydrates may facilitate early expression of the genetic trait $(9,10)$. In this study. mean plasma triglyceride in 43 children with familial hypertriglyceridemia fell after 6 months of weight reduction-NIH type IV diet (5) from $253 \pm 32$ to $116 \pm 8 \mathrm{mg} / \mathrm{dl}$, $P<0.01$. The mean decrement in weight $(1 \pm 1 \mathrm{~kg})$ was not significant. and decrements in weight failed to correlate with decrements in plasma triglycerides, $r=0.131$. Despite this failure to appreciably reduce weight, after 6 months on diet. plasma triglyceride levels were reduced to normal $(<140 \mathrm{mg} / \mathrm{dl})$ in 32 of the 4.3 children.

On subsequent follow-up for $8-26$ months (in 19 subjects) most of the children were in a rapid pubertal growth phase and separation of the effects of caloric restriction and the compositional restrictions of the type IV diet cannot be made. Dietary effect is an amalgamation of caloric restriction (where indicated) and modification of dietary constituents. At 8 months' follow-up in 1.3 children, mean plasma triglyceride was $170+31$. compared to baseline levels of $290 \pm 86 \mathrm{mg} / \mathrm{dl}, P<0.01$, and 5 of the 13 had normal triglyceride levels. Plasma triglycerides were normal in 4 of 5 children at evaluation at 1 year, in 3 of 7 at 18 months, and in 4 of 14 at 22-26 months. When weight gain was proportionately greater than accretion of height. and where no attention to either caloric intake or composition was given, triglycerides remained elevated, whereas dietary adherence was generally accompanied by reduced or normal triglycerides.

Although we urged all of the 46 children in the initial intensive 6-month study group to continue with routine 2-4-month evaluations over time, only a minority continued in the re-evaluation program. The sharp reductions in plasma triglyceride after 6 months follow-up apparently misled many parents-children-physicians that the levels would remain normal without repetitive rexamination, caution as to total caloric intake, and dietary re- 
Table 2. Plasma triglyceride (T(i), baseline, and on diet (milligrams per dl)

\begin{tabular}{|c|c|c|c|c|c|c|c|c|c|c|c|}
\hline & & & & & & Months & of follow-up & & & & \\
\hline $\begin{array}{l}\text { Subject } \\
\text { no. }\end{array}$ & Basclinc & 8 & 10 & 12 & 14 & 16 & 18 & 20 & 22 & 24 & 26 \\
\hline $3 \mathrm{Ht} / \mathrm{Wt}^{\prime}$ & $\begin{array}{l}16.5 / 61 \\
197\end{array}$ & & & & & & & & & $166.5 / 69.8$ & \\
\hline $\begin{array}{l}\text { TG } \\
4 \mathrm{Ht} / \mathrm{Wt}_{\mathrm{t}}\end{array}$ & $\begin{array}{l}197 \\
169 / 100\end{array}$ & $172 / 1113$ & $173 / 110$ & & & & & & & & \\
\hline $\mathrm{TG}$ & 222 & $(228)^{2}$ & $(9(0)$ & & & & $\begin{array}{l}17+/ 104 \\
(12.3)\end{array}$ & & & & \\
\hline $6 \mathrm{Ht} / \mathrm{Wt}$ & $145 / 47$ & $148 / 52$ & & $150 / 54$ & & & $1.50 / 57.5$ & & & $152 / 58$ & \\
\hline TC; & 304 & $(119)$ & & $(95)$ & & & $(104)$ & & & $(118)$ & \\
\hline $7 \mathrm{Ht} / \mathrm{Wt}$ & $157.5 / 58.6$ & & & & & $161 / 69$ & $162 / 7.3$ & & $162.5 / 78$ & & \\
\hline TG & 3.32 & & & & & $298^{: 3}$ & $414^{:}$ & & $184^{4}$ & & \\
\hline $8 \mathrm{Ht} / \mathrm{Wt}$ & $168 / 79.2$ & & & & & & & & & $190.5 / 108.6$ & \\
\hline $\begin{array}{l}\mathrm{TC} \\
\varphi \mathrm{Ht} / \mathrm{Wt}\end{array}$ & 400 & & & & & & & & & $(81)$ & \\
\hline $\begin{array}{l}\mathrm{TC} \\
l 0 \mathrm{H} / \mathrm{Wt}\end{array}$ & $\begin{array}{l}2(1) \\
1.30 / 25.4\end{array}$ & $(1.30)$ & & & $1.3 .5 / 28.6$ & & & & & $2+1^{3}$ & \\
\hline TG & $\begin{array}{l}1.3(1 / 25.4 \\
1.54\end{array}$ & & & & $(12)$ & & & & & & \\
\hline$\| \mathrm{Ht} / \mathrm{Wt}$ & $155 / 61$ & & & & & & & & & $165.5 / 74.5$ & \\
\hline TG & 148 & & & & & & & & & $216^{3}$ & \\
\hline $14 \mathrm{Ht} / \mathrm{Wt}$ & $175 / 104.5$ & $175 / 113.4$ & & & & & & & & & \\
\hline TC; & 221 & $\begin{array}{l}212: 3 \\
167.7 / 69\end{array}$ & & & & & & & & & \\
\hline $1.5 \mathrm{Ht} / \mathrm{Wt}$ & $167.7 / 60$ & $167.7 / 69$ & & $167.7 / 69$ & & & $167.7 / 68.7$ & & & & \\
\hline TC; & 217 & $(154)$ & & $320^{4}$ & & & $(211)$ & & & & \\
\hline $16 \mathrm{Ht} / \mathrm{Wt}$ & $160 / 56$ & $161 / 56$ & & $161 / 57.4$ & & & $161 / 57.4$ & & & & \\
\hline $\mathrm{TC}$ & 160 & $(48)$ & & $(97)$ & & & $(96)$ & & & & \\
\hline $26 \mathrm{Ht} / \mathrm{Wt}$ & $175 . .3 / 68.2$ & $179 / 68.8$ & & & & & & & & & \\
\hline TCi & 220 & $(156)$ & & & & & & & & & \\
\hline $28 \mathrm{Ht} / \mathrm{Wt}^{2}$ & $16.3 / 48$ & $170 / 56$ & & & & & & & & $172.7 / 56.1$ & \\
\hline $\mathrm{TC}$ & 210 & $(75)$ & & & & & & & & $(56)$ & \\
\hline $31 \mathrm{Ht} / \mathrm{Wt}$ & $177.8 / 75$ & $180 / 74$ & & & & & $180(1 / 75.5$ & & & $180.5 / 76.5$ & \\
\hline TC & 187 & $(116)$ & & & & & $(181)$ & & & $(206)$ & \\
\hline $.34 \mathrm{Ht} / \mathrm{Wt}$ & $18.3 / 81$ & & & & & & & & & $183 / 89$ & \\
\hline TC; & 400 & & & & & & & & & $464^{3}$ & \\
\hline $37 \mathrm{Ht} / \mathrm{Wt}$ & $158 / 60.4$ & $158 / 62$ & & & & $158 / 70 .+$ & & & & $158 / 64.5$ & \\
\hline $\mathrm{TC}$ & 1.320 & $5-2^{4}$ & & & & $606^{3}$ & & & & $(162)$ & \\
\hline $38 \mathrm{Ht} / \mathrm{Wt}$ & $168 / 55$ & $160 / 53$ & & $170 / 52$ & & $17.3 / 58$ & & $174 / 59$ & & $174 / 6.5 .2$ & \\
\hline TC; & 196 & $(154)$ & & $(98)$ & & $(182)$ & & $(124)$ & & $238^{3}$ & \\
\hline $44 \mathrm{Ht} / \mathrm{Wt}$ & $1+9 / 56$ & $155 / 62$ & $155 / 601.2$ & $156 / 60)$ & $157 / 62$ & & $1.57 / 6 x$ & & $1.58 .5 / 6+.3$ & & \\
\hline TC; & $1+2$ & $(170)$ & $(1+8)$ & $(109)$ & $(105)$ & & $21 x^{4}$ & & $(126)$ & & \\
\hline $54 \mathrm{Ht} / \mathrm{Wt}$ & $177 / 91$ & $177 / 88.2$ & & & & & & & & $18.3 / 97$ & \\
\hline TC; & 170 & $(1+9)$ & & & & & & & & $(1+.5)$ & \\
\hline $55 \mathrm{Ht} / \mathrm{Wt}$ & $1.56 / 45$ & & & & & & & & & $158 / 46.1$ & \\
\hline TCi & $1+4$ & & & & & & & & & $1+4^{3}$ & \\
\hline
\end{tabular}

instruction. As shown in Table 2 this was not the case, although plasma triglyeerides were generally normal in those children who followed a consistent long range dict program.

\section{(C)NCIIUSION}

Amelioration of familial hypertriglyceridemia on the NIH type IV diet is a realizable goal in children. but requires persistent. repetitive reexamination and re-instruction. Normalization of triglyeride levels in children may be important as a primary. longitudinal approach to reduction of the increased atherosclerotic risk attendant to familial hypertriglyecridemia in some (2. 3), hut not all adults with familial hypertriglyceridemia (1).

\section{RIFERIN(}

1. Brunzell. J. D., Schrolt. H. (i.. Motuslkt. A. G.. and Bierman. 1. I.. Myocardial infarction in familial form of hypertriglyceridemia. Metahodism $2.5(3): 313(1476)$

2. Carlon. I. A.. and Bottiger. 1. F.: Ischemic heart-discase in relation to fasting values of plasma triglycerides and cholesterol. Lancet, $i: 865$ (1972).

3. Carlson. I. A., and Fricson. M.: Quantitative and qualitative serum lipopro- rein analysis. 2. Studies in male survisors of myocardial infarction. Athereackerosis. $21:(3): 435(1975)$.

4. Fredrickoon. D S and L asy R 1. Familial hyperlipoproteinemia. In: J. B Stanhury. J. B. Wyngatarden, and D). S. Fredrickson: The Metabolic Basio of Inherited Discase. Fd. 3. P. 5.5 (Mc(irath-Hill. New York. 1972)

5. Fredrickson. D. S.. I ewy. R. 1. Jone, E.. Bonell. M., and Eamst. N.: The Dietary Management of Hyperlipenproteinemia: A Handhook for Physcians. P. X3, (United States Department of Health. Fducation and Welfare. Public Health Service. Warhington. D. ( .. 1970).

6. Cilueck. ( . J. Fallat, R. W. Mellies, M. J., and Stciner. P. M.: Pediatric familial type III hyperlipoproteinemia. Metatoolism. 25: 1269)(1976)

7. Gilueck. ( J., Fallatt. R. W and Tsang. R.: Pediatric familial type II hyperlipoprotememia: Therapy with deet and cholestyramine resin. Pediatrics. 52: $669(197.3)$

X. Cilueck. ( . J., Fallat, R. W.. and Tsang. R.: Hypercholesterolemia and hypertriglyceridemia in ehildren: A pediatric approach to primary atherer scleresis prevention. Amer. J. Dis. (hild. 128: 569 (1474).

9. Cilueck. (. J.. Mellies, M. J.. Srivastava, I.. Knowles, H. C.. Jr., Fallat, R. W. Tsang. R. ('. Wacholder. S... and Buncher, (C. R.: Insulin, ohesits, and triglyceride interrelationships in 16 children with familial hypertriglyceridemia. Pediat. Res.. 10(4): 409 (1976).

10. (ilueck. C. J.. Tsang. R.. Fatlat, R., Buncher, C. R. . Fians, G .. and Steiner. P.: Familial hypertriglyceridemia: Studies in 130 children and 45 sibling of 36 index case's. Metaholism. 22: 1287 (197.3)

11. (ilueck, C'. J., Tsang, R. C'., Fallat, R. W., and Mellies, M. J.: Diet in children 
heterozygous for familial hypercholesterolemia. Amer. J. Dis. Child.. 1.31: 162 (1977)

12. Lipid Research Clinics Program: Manual of Lahoratory (Operations, Vol. 1 (United States Government Printing Office, Washington. D.(... 1974).

1.3. Snedecor, (;. W., and Cochran, W. G.: Statistical Methods, Fd. 6. p. 128 (Iowa State University Press. Ames, Iowat, 1967).

14. Snedecor. (i. W.. and Cochran. W. (i.: Statistical Methods, Fd. 6. p. 172 (lowa State University Press. Ames, lowa, 1967).

15. Snedecor. G. W., and Cochran, W. G.: Statistical Methods, Fd. 6. p. 194 (lowa State University Press, Ames, lowa, 1967).

16. The steps described in this manuscript were done with the formal approval of the University of C'incinnati Faculty Committee on Human Research and the General Clinical Research Center Advisory Committec. and with signed informed consent.

17. A portion of this nork was supported by the General Clinical Research Center Cirant RR 00068-14, and a portion of this work was done during Dr. Glueck's tenure as an Fstablished Investigator of the American Heart Association, 1971-1976.

18. Requests for reprints should be addresed to: (') J (ilueck M D University of Cincinnati, General Clinical Research (enter. ("incinnati General Hospital. 2.34 (ioodman St., Cincinnati, Ohio 45267 (USA)

19. Received for publication December 17.1976

20. Accepted for publication February 15, 1977.

\title{
Low and High Density Lipoprotein Cholesterol Interrelationships in Neonates with Low Density Lipoprotein Cholesterol $\leq$ the 10th Percentile and in Neonates with High Density Lipoprotein Cholesterol $\geq$ the 90th Percentile
}

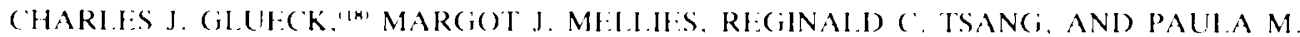 \\ STIIINI:R

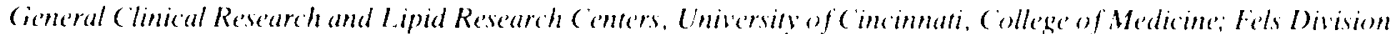

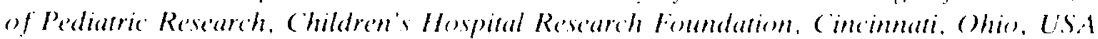

\section{Summary}

Since the inverse relationship between high density lipopro. tein cholesterol (C-HDI.) and low density lipoprotein cholesterol (C-L.DI) is generally recognized in school children and in adults, but not at birth, the current study was focused on neonates having $C$-HDL $:$ the 90 th percentile and neonates with $C$. LDL : the 10 th percentile to determine whether any distinctive relationships existed at the extreme limits of the frequency distribution among C-HDL, C-L.DL, and total plasma cholesterol. Sixty-three neonates with $C-L D L \leq$ the 10 th percentile $(20 \mathrm{mg} / \mathrm{dl})$, and 58 with $\mathrm{C}$-HDL, the 90 th percentile $(50 \mathrm{mg} /$ dl) were selected in the consecutive order of their birth as part of an ongoing cord blood lipid and lipoprotein survey. Comparisons of the hypobeta- and hyperalphalipoproteinemic neonates with 117 previously described unselected neonates were made. In the 117 unselected neonate controls, both C-HDI and CLDL levels were closely correlated with total cord blood cholesterol $(r=0.63,0.76, P<0.01)$, whereas $C$-HDL was not significantly related to $C \cdot L D L,(r=0.002)$. In the 63 hypobetalipoproteinemic neonates, $C$-HDL correlated closely with total plasma cholesterol concentrations $(r=0.98, P$ (0.01). C-I.DI failed to correlate with total plasma cholesterol $(r=0.07)$. In the face of low cord blood C.L.DL, nearly all of the total plasma cholesterol variation was accounted for by C-HDL. C-HDL was not significantly related to C-L.DL $(r=-0.15)$. In 58 hyperalphalipoproteinemic neonates, C-HDL did not significantly correlate with total cholesterol concentrations $(r=0.22)$, whereas C-LIDI, was closely related $(r=0.88, P-0.01)$, with nearly all of the total plasma cholesterol variation accounted for by $C$ L.DL. The inverse C-HDL, to C-I.DL relationship was not significant $(r=-0.18)$

\section{Speculation}

Whatever factors contribute to both the overall and to the extremes of the C-HDL and C-L.DL frequency distributions at birth, C-HDL and C-I.DL in neonates appear to be under independent metabolic control.

Plasma high density lipoprotein cholesterol levels in adults are often inversely correlated with low density lipoprotein cholesterol levels $(1,3,7,8)$. In the Bogalusa lipoprotein study in white and black school children, total plasma cholesterol and (I.DI. levels were closely correlated $(r=0.745 .0 .727)(12)$. Total plasma cholesterol atso correlated with ('-HDI concentrations in whites and blacks $(r=0.4+1, r=0.595)$ (12). The Bogalusa study (12) revealed significant inverse relationships between (-HDI and (-1.DI. levels in $117+$ black children $(r=$ $-0.09)$, and in 2009 white children $(r=-0.231)$. The correlattion in black children $(r=-0.09)$ between (-HDI and (-I.DI., although statistically significant, is low, and perhaps of douhtful biologic import. Rhoads o't al. (9) found no significant correlation between (-HI) and (-L.D) $(r-0.01)$ and concluded that "the inverse relation of alpha cholesterol to prevalence of coronary heart discase was independent of heta cholesterol (9). 